critical to many international commodity supply chains, are key to the conservation of the biome.

In recognition of the roles of farmers and corporations in biodiversity conservation, Fauna \& Flora International, Souza Cruz (a subsidiary of British American Tobacco) and the Brazilian NGO Sociedade de Pesquisa em Vida Selvagem e Educação Ambiental (Society for Wildlife Research and Environmental Education) partnered with 17 smallholder farmers in Paula Freitas municipality, Paraná, in a 4-year project Parcerias pela Biodiversidade (Partners for Biodiversity), which was completed in December 2015. The partners built knowledge of financial and legislative frameworks, enabling and constraining factors for farmers, and the costs and benefits of practical interventions to improve biodiversity and ecosystem services on farms. Interventions included forest restoration, enhancing habitat for pollinators, removal of invasive species, and management of crops to reduce fertilizer use. The results demonstrate that costs of interventions, particularly restoration, are significantly less than previously reported. For example, tree-planting restoration techniques, which include labour costs for planting, maintenance for 2 years and native seedlings from local state nurseries, were found to be cheaper (BRL 6,100, USD 1,610, per ha) than expected. This can be explained in part by not using agrochemicals and by implementation being carried out by farmers and hired labour rather than project staff. In addition, fencing (at USD 200-300 per $100 \mathrm{~m}$, including labour) to exclude livestock can result in significant early natural forest regeneration in areas with previous low-impact land use. Monitoring from 2013 to date by farmers and project staff demonstrated the success of these actions: $<10 \%$ mortality of planted seedlings, good average growth $(2 \mathrm{~m})$ of diverse native plants in naturally regenerating areas, $23 \%$ increase in maize yield and $25 \%$ reduction in urea application by using inoculants, and a reported increase in fruit yield as a result of an increase in pollinators.

We used InVEST to map and value some key ecosystem services influenced by the interventions. The models for carbon, crop pollination, and sediment and nutrient retention spatially prioritized areas to improve ecosystem services and estimate economic gains by comparing the pre-project landuse scenario with two riparian forest restoration scenarios (10 and $30 \mathrm{~m}$ wide buffers). Estimated revenues derived from reduced costs of soil recovery, water treatment and dredging, and value of carbon credits, represented total potential annual gains of USD 509,000 and 177,000 in the 30- and 10-m scenarios, respectively. Including the opportunity cost of forgoing usual economic activity in riparian zones, the potential annual ecosystem service benefits from the $30-$ and $10-\mathrm{m}$ scenarios equate to USD 750 and 270 per farm, respectively.

The Brazilian Forest Code requires that landowners maintain or restore forest in areas delivering ecosystem services. The project demonstrated clear economic benefits for complying with and going beyond the requirements of the Forest Code. To realize these benefits, frameworks such as payments for ecosystem services need to be established. Such mechanisms are increasingly used in Brazil and elsewhere as the economic case for biodiversity management in farming landscapes becomes recognized. The frameworks are most effective when private landowners, NGOs, government agencies and companies form partnerships to realize common, sustainable land management goals.

JoÃo Guimarães and Steven Lowe Agricultural Landscapes, Fauna \& Flora International, Cambridge, UK

E-mail steven.lowe@fauna-flora.org

\section{7th Student Conference on Conservation Science}

'There is a darkness threatening the biodiversity of this planet. There is one generation that can act.' No, not a line from a new blockbuster film, but the words of the RSPB's Chief Executive as he opened the 17th Student Conference on Conservation Science (SCCS).

More so than in perhaps any other field in biology, young conservationists may feel overwhelmed by the tasks that lie ahead. Conservation is poised to become increasingly interdisciplinary, international and ambitious, and it must also gather pace. It is encouraging therefore to see the SCCS in its 17 th year, with 161 graduate student delegates (including myself) attending the most recent conference on 24-26 March 2016 in the Department of Zoology, University of Cambridge, UK.

A varied programme of plenary lectures stimulated discussion covering the length and breadth of conservation, from fieldwork to policy and business. Taylor Ricketts of the University of Vermont, USA, took the much-discussed topics of ecosystem services and pollinators and through elegant field studies provided a new and quantified perspective. Nancy Knowlton of the Smithsonian Institution, USA,

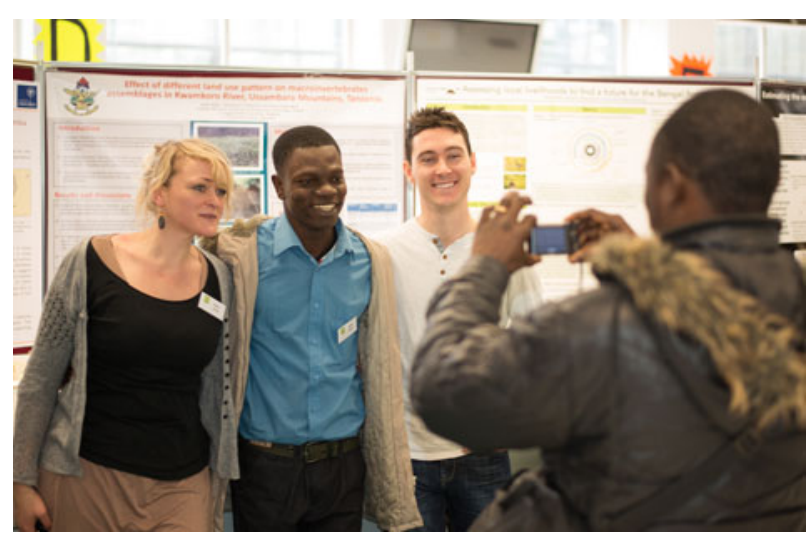

New friendships developing at the 17th Student Conference on Conservation Science, Cambridge, UK. Copyright Gorm Shackelford 
shared success stories on the theme of \#OceanOptimism, and Mike Barry from UK retailer Marks \& Spencer gave an unfamiliar perspective from business.

For this young conservationist, a highlight was the insightful evening lecture from Tom Brooks, IUCN, Switzerland, entitled simply Does conservation work? The answer was a robust and resounding yes, we simply need more of it: heartening words from someone at the centre of global conservation efforts.

A series of workshops (a feature that sets SCCS apart from many conferences) gave delegates a chance to experience primers on broad topics such as statistics, genetics and experimental design or hear from experts such as Oryx's editor Martin Fisher, and Bill Sutherland, who leads Conservation Evidence. The body of the conference consisted of 32 talks from students who had come from as far afield as Iran, Madagascar and Cambodia (and as close as Cambridge). Most other delegates brought posters, which generated engaging discussion during the coffee breaks and lunch sessions.

Attending conferences, presenting research, and networking are important parts of our development as scientists. But SCCS goes further, providing an opportunity for early-career conservationists to immerse themselves among like-minded people from all around the world-an opportunity not to miss.

The next Cambridge SCCS will take place during 28-30 March 2017. Updates will be posted on the conference website (http://www.sccs-cam.org). There are now sister SCCS series in Australia, China, Hungary, India and the USA. Dates and application details are on the SCCS Cambridge website, http://www.sccs-cam.org.

JAMES BoRRELL Schools of Biological and Chemical Sciences, Queen Mary, University of London, London, UK

E-mail j.s.borrell@qmul.ac.uk

\section{7th International Conservation Workshop for Arabia's Biodiversity}

The 17th Annual International Conservation Workshop for Arabia's Biodiversity was held at the Breeding Centre for Endangered Arabian Wildlife in Sharjah, United Arab Emirates, on 8-11 February 2016. This regional forum brought together over 150 participants representing UAE, Jordan, Saudi Arabia, Bahrain, Kuwait, Yemen, Oman, Qatar and Iraq, as well as from the UK, USA, South Africa, Italy and New Zealand. The Sharjah workshops are hosted by the Environment and Protected Areas Authority of the Government of Sharjah, under the patronage of H.H. Sheikh Dr Sultan bin Mohammed al Qasimi, Member of the Supreme Council and Ruler of Sharjah.

The 17th Workshop had four themes. A species assessment theme conducted a review of the distribution and conservation status of all mammals in the Arabian region. The protected areas and planning theme worked in conjunction with mammal assessments to compile an up-to-date register of all biodiversity of protected areas in the region, to facilitate an evaluation of current mammal protection and future needs. The veterinary theme looked at the issue of wild ungulate disease diagnosis and management, with an emphasis on tuberculosis, and was expanded to consider the complications associated with mass game capture and the use of short- and long-acting tranquillizers.

Two working groups conducted a regional Red List assessment of all species of terrestrial mammals in the Arabian region, the Arabian Peninsula and Syria and Iraq. Over 160 species were assessed. In association with this assessment, a comprehensive compilation of summary data on biodiversity in protected areas was completed. Over 150 protected areas were identified, and the boundaries of key areas were mapped to facilitate a gap analysis of current and future conservation needs for threatened mammal taxa. A third working group reviewed the status and distribution of the 22 species of marine mammals in the Arabian region, the first time this exercise has been carried out.

The lack of species-specific diagnostic tests for tuberculosis, diagnostic capacity in the region, and transparency make this a very difficult disease to control. This year there was a combined workshop session looking at threats to the mammals of the region, acknowledging that veterinarians and conservation managers are part of the One Health concept that looks at the interface between humans, animals and the environment, including the diseases threatening livestock, free-roaming wildlife, and humans.

PHILIP SEDDON Department of Zoology, University of Otago, Dunedin, New Zealand.E-mail philip.seddon@otago.ac.nz

MIKE KNIGHT South African National Parks, \& Centre for African Conservation Ecology, Nelson Mandela Metropolitan University, Port Elizabeth, South Africa

GeRHARD STEENKAMP Department of Companion Animal Clinical Studies, Faculty of Veterinary Science, University of Pretoria, Ondeserspoort, South Africa

Craig Hilton-Taylor IUCN Red List Unit, The David Attenborough Building, Pembroke Street, Cambridge, UK

DAVID MaLlon Manchester Metropolitan University, UK, \& IUCN/Species Survival Commission Conservation Planning Sub-Committee

\section{The Whitley Awards 2016}

The annual Whitley Awards Ceremony was held on 27 April 2016 at the Royal Geographical Society in London. The 